\title{
Fuzzy Diagnosis Procedure of the Types of Glaucoma
}

\author{
Vijay Kumar \\ Assistant Prof. in Mathematics, \\ Delhi College of Tech.\& Mgt., \\ Palwal
}

\author{
Isha Bharti \\ Scholar, Deptt. Of Applied \\ Physics., Delhi Tech. \\ University (DTU), Delhi.
}

\author{
Y. K Sharma \\ A. P (Sr. Scale) in Maths., \\ Ansal Inst. of Tech., Gurgaon.
}

\begin{abstract}
In this paper, we propose a fuzzy method for the diagnosis of the types of glaucoma. This method is based on the relations between the symptoms and diseases by intuitionistic fuzzy sets (IFS). For this purpose, we develop a hypothetical medical information with assigned degree of membership and degree of non-membership based on the relation between symptoms and various types of glaucoma.
\end{abstract}

\section{Keywords}

Intuitionistic fuzzy sets(IFS), Fuzzy relations, Medical information.

\section{INTRODUCTION}

The functioning of the human body is quite complex and highly interactive interplay of its organs. That is why, Medical diagnostic investigations are very complex and difficult. Patients coming to the doctor show symptoms and signs, and the doctor will conclude which disease these phenomena mean. This is an error-prone process. Sometimes, doctor subjects the patient to physical examination or some laboratory tests from which he obtains more or less objective data. These tests may overlook important indications or fail to carry out a complete examination.

In this paper, we describe an attempt to provide a formal model of the process to diagnose the type of glaucoma by using IFS theory and implement it in the form of treatmentrecommendation system. This is the system by which the physician uses his medical knowledge to infer a diagnosis from the symptoms displayed by the patient, his lab test results and medical history.

Losch [8], suggested the process of diagnosis of glaucoma by using fuzzy sets. Kumar, Biswas and Roy [7], Ahn [2] using the applications of IFS theory in diagnosis of various types of diseases. Here, are suggest the formal method of diagnosis of the type of glaucoma by using generalized fuzzy set theory.

Glaucoma is a group of diseases that can damage the eye's optic nerve, the nerve that carries visual information from the eye to the brain and result in vision loss and blindness. Glaucoma occurs when the normal fluid pressure called intraocular pressure (IOP) inside the eyes slowly rises and damages the optic nerve. There are no early warning signs or symptoms. A comprehensive medical history is important in identifying the disease. Glaucoma has many causes and symptoms and is one of the most common reason for blindness. Broadly, there are four major types of glaucoma:
1. Open-angle (chronic) glaucoma
2. Angle-closure (acute) glaucoma
3. Congenital glaucoma
4. Secondary glaucoma

\begin{abstract}
Also, there are four important factors influence in the diagnosis of glaucoma:

1. Intraocular pressure.

2. The condition of the optic nerve.

3. The patient's visual field.

4. The angle where the iris meets the cornea.
\end{abstract}

Here, the term symptom is used for any information about the patient's state of health, i.e, optic nerve imaging, retinal examination, visual field findings etc. In other words, we find the causes of above mentioned factors. Based on this information a physician has to find a list of diagnostic possibilities for the patient.

To diagnosis Glaucoma: Firstly, we establish IF relation between patients and symptoms of Glaucoma with hypothetical assigned degree of membership and nonmembership elements as explained in table (3.1). Secondly, we establish IF relation between symptoms of Glaucoma and the type of Glaucoma with assigned degree of membership and non-membership elements as explained in table (3.2) by taking hypothetical medical information of the patients and the diseases. Finally, we determine a new measure for diagnosis the type of glaucoma on the basis of Max-min-max composition of IF relations as explained in table (3.3). The highest weight for each patient from possible diagnosis gives the solution as explained in table (3.4). If there is a tie in weight elements, then patient may have the risk of both kind of glaucoma.

\section{BRIEF INTRODUCTION TO IFS}

Zadeh [11], For a fixed set $X$, fuzzy set of $A$ is defined as :

$A=\left\{<x, \mu_{A}(x)>\mid x \in X\right\}$,

Where, $\mu_{A}(x): X \rightarrow[0,1] \quad$ define the degree of membership of the element $x \in X$ to the set $A$. 
Atanassov [4, 5], For a fixed set $X$, an IFS of $A$ is defined as :

$$
A=\left\{<x, \mu_{A}(x), v_{A}(x)>\mid x \in X\right\},
$$

where $\mu_{A}(x): X \rightarrow[0,1]$ and $v_{A}(x): X \rightarrow[0,1]$ define the degree of membership and degree of nonmembership of the element $x \in X$ to the set $A$.

For every $x \in X, 0 \leq \mu_{A}(x)+v_{A}(x) \leq 1$ and the amount $\pi_{A}(x)=1-\mu_{A}(x)-v_{A}(x)$ is called the intuitionistic index or hesitation index, which may require to membership value, non-membership value or both.

It is noted that Fuzzy sets are intuitionistic fuzzy sets(IFS) but converse is not necessarily true.

Further, Let $A$ be an IFS of the set $X$ and let $R$ be an IF relation from $X \rightarrow Y$, then

Max-min-max composition $B$ [Biswas, [6]] of IFS $X$ with the IF relation $\mathrm{R}(X \rightarrow Y)$ is defined as $B=R o A$ with membership and non-membership function defined as:

$$
\mu_{B}(y)=\max _{x \in X}\left\{\min \left[\mu_{A}(x), \mu_{R}(x, y)\right]\right\}
$$

$$
v_{B}(y)=\min _{x \in X}\left\{\max \left[v_{A}(x), v_{R}(x, y)\right]\right\}
$$

Adlassnig [1], Ahn[2, 3] elaborated medical knowledge as fuzzy relation between symptoms and disease. Let $S=\left\{s_{1}, s_{2}, \ldots \ldots \ldots \ldots \ldots, s_{m}\right\} ;$

$$
D=\left\{d_{1}, d_{2}, \ldots \ldots \ldots \ldots . . ., d_{n}\right\} \text {; }
$$

$P=\left\{p_{1}, p_{2}, \ldots \ldots \ldots \ldots \ldots . . ., p_{q}\right\} ;$ be the finite set of symptoms, type of diseases and patients respectively.

According to Adlassnig [1] , two fuzzy relations(FR), $Q$ and $R$ are defined as:

$Q=\left\{<(p, s), \mu_{Q}(p, s), v_{Q}(p, s)>\mid(p, s) \in P \times S\right\}$

$$
R=\left\{<(s, d), \mu_{R}(s, d), v_{R}(s, d)>\mid(s, d) \in S \times D\right\}
$$

Where $\mu_{Q}(p, s)$ indicate the degree to which the symptom $s$ appears in patient $p$ and $v_{Q}(p, s)$ indicate the degree to which the symptom $S$ does not appears in patient $p$.
Similarly, $\mu_{R}(s, d)$ indicate the degree to which the symptom $s$ confirm the disease $d$ and $v_{R}(s, d)$ indicate the degree to which the symptom $S$ does not confirms the disease $d$.

The composition $T$ of IFRs $R$ and $Q(T=R \circ Q)$ describe the state of patient $p_{i}$ in terms of the diagnosis of Glaucoma from $P$ to $D$ given by membership and nonmembership as :

$\mu_{T}\left(p_{i}, d\right)=\max _{s \in S}\left\{\min \left[\mu_{Q}\left(p_{i}, s\right), \mu_{R}(s, d)\right]\right\}$

(2.5) and

$v_{T}\left(p_{i}, d\right)=\min _{s \in S}\left\{\max \left[v_{Q}\left(p_{i}, s\right), v_{R}(s, d)\right]\right\}$,

(2.6) $\forall p_{i} \in P$ and $d \in D$.

We can estimate the type of glaucoma to patients by using the information obtained from the table (3.1) and (3.2) of given hypothetical medical information. This information play a significant role in diagnosis when many types of glaucoma are presented in patients.

From $Q$ and $R$, one may compute new measure of IFR $T$ for which, in general, the diagnostic labels of patient $p$ for any type of disease $d$ such that the following is to be satisfied:

This new measure of $T$ will translate the higher degrees of association and lower degree of non-association of symptoms as well as lower degrees of intuitionistic index to the diagnosis.

If there is almost equal values for different diagnosis in $T$ is obtained, we consider the case for which intuitionistic index is least.

To see the application of the method, let us frame a hypothetical medical information of the patients:

\section{MEDICAL INFORMATION}

Let $P=\left\{p_{1}, p_{2}, p_{3}, p_{4}\right\}$ be the set of patients and $S=\left\{s_{1}, s_{2}, s_{3}, s_{4}\right\}$ be the set of symptoms of glaucoma present in patients.

Suppose the IFR $Q(P \rightarrow S)$ is given by (hypothetically): 


\begin{tabular}{|c|c|c|c|c|c|c|c|c|}
\hline$Q$ & \multicolumn{2}{|c|}{$S_{1}$} & \multicolumn{2}{|c|}{$S_{2}$} & \multicolumn{2}{|c|}{$S_{3}$} & \multicolumn{2}{|c|}{$S_{4}$} \\
\hline 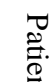 & $\mu_{Q}$ & $v_{Q}$ & $\mu_{Q}$ & $v_{Q}$ & $\mu_{Q}$ & $v_{Q}$ & $\mu_{Q}$ & $v_{Q}$ \\
\hline$P_{1}$ & 0.8 & 0.1 & 0.6 & 0.1 & 0.2 & 0.8 & 0.6 & 0.1 \\
\hline$P_{2}$ & 0.0 & 0.8 & 0.4 & 0.4 & 0.6 & \begin{tabular}{|l|}
0.1 \\
\end{tabular} & 0.1 & 0.7 \\
\hline$P_{3}$ & 0.8 & 0.1 & 0.8 & 0.1 & 0.0 & 0.6 & 0.2 & 0.7 \\
\hline$P_{4}$ & 0.6 & 0.1 & 0.5 & 0.4 & 0.3 & 0.4 & 0.7 & 0.2 \\
\hline
\end{tabular}

Table (3.1)

Let $D=\left\{\begin{array}{l}\text { open angle }(\text { chronic }), \text { Angle closure } \\ (\text { acute }), \text { Congenital, Secondary }\end{array}\right\}$ be the set of type of glaucoma.

Suppose the IFR $R(S \rightarrow D)$ is given by (hypothetically):

\begin{tabular}{|c|c|c|c|c|c|c|c|c|}
\hline$R$ & $\begin{array}{l}\text { ope } \\
\text { (ch }\end{array}$ & $\begin{array}{l}\text { angle } \\
\text { nic) }\end{array}$ & $\begin{array}{l}\text { Ang } \\
\text { clos } \\
(\text { act }\end{array}$ & & $\mathrm{Cor}$ & genital & Secc & ndar \\
\hline 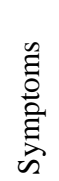 & $\mu_{R}$ & $v_{R}$ & $\mu_{R}$ & $v_{R}$ & $\mu_{R}$ & $v_{R}$ & $\mu_{R}$ & $v_{R}$ \\
\hline$S_{1}$ & 0.4 & 0.0 & 0.7 & 0.0 & 0.3 & 0.3 & 0.1 & 0.7 \\
\hline$S_{2}$ & 0.3 & 0.5 & 0.2 & 0.6 & 0.6 & 0.1 & 0.2 & 0.4 \\
\hline$S_{3}$ & 0.1 & 0.7 & 0.0 & 0.9 & 0.2 & 0.7 & 0.8 & 0.0 \\
\hline$S_{4}$ & 0.4 & 0.3 & 0.7 & 0.0 & 0.2 & 0.6 & 0.2 & 0.7 \\
\hline
\end{tabular}

Table (3.2)

The Composition $T=R \circ Q$ is follows as:

\begin{tabular}{|c|c|c|c|c|c|c|c|c|}
\hline$T$ & $\begin{array}{l}\text { ope } \\
\text { (ch }\end{array}$ & $\begin{array}{l}\text { angl } \\
\text { onic) }\end{array}$ & $\begin{array}{l}A n \\
(a c\end{array}$ & clos & $\mathrm{Cor}$ & genital & $\mathrm{Sec}$ & ndary \\
\hline ت. & $\mu_{T}$ & $v_{T}$ & $\mu_{T}$ & $v_{T}$ & $\mu_{T}$ & $v_{T}$ & $\mu_{T}$ & $v_{T}$ \\
\hline$P_{1}$ & 0.4 & 0.1 & 0.7 & 0.1 & 0.6 & 0.1 & 0.2 & 0.4 \\
\hline$P_{2}$ & 0.3 & 0.5 & 0.2 & 0.6 & 0.4 & 0.4 & 0.6 & 0.1 \\
\hline$P_{3}$ & 0.4 & 0.1 & 0.7 & 0.1 & 0.6 & 0.1 & 0.2 & 0.4 \\
\hline$P_{4}$ & 0.4 & 0.1 & 0.7 & 0.1 & 0.5 & 0.3 & 0.3 & 0.4 \\
\hline
\end{tabular}

Table (3.3)

Now, we calculate $S_{T}$ :

\begin{tabular}{|l|l|l|l|l|}
\hline$S_{T}$ & $\begin{array}{l}\text { open angle } \\
(\text { chronic })\end{array}$ & $\begin{array}{l}\text { Angle } \\
\text { closure } \\
(\text { acute })\end{array}$ & Congenital & Secondary \\
\hline$P_{1}$ & 0.35 & 0.68 & 0.57 & 0.04 \\
\hline$P_{2}$ & 0.20 & 0.08 & 0.32 & 0.57 \\
\hline$P_{3}$ & 0.35 & 0.68 & 0.57 & 0.04 \\
\hline$P_{4}$ & 0.32 & 0.68 & 0.44 & 0.18 \\
\hline
\end{tabular}

Table (3.4)

From the table(3.4), we conclude that patient $p_{1}, p_{3}$ and

$p_{4}$ are suffering from Angle closure(acute) type of glaucoma. If a patient has this type of glaucoma in one eye, the risk for an attack will occur in the second eye if it is not treated. Where as, patient $p_{2}$ is suffering from Congenital type of glaucoma and is the hereditary one.

\section{CONCLUSION}

In this paper, the study of medical diagnosis of the types of glaucoma has been made with the generalized concept of fuzzy set theory by taking a hypothetical medical knowledge theory. It is possible to classify the type of glaucoma using the above mentioned method. Also, by this method, we can differentiate patients according to the type of glaucoma they suffer from. This method is an efficient tool for medical decision making problem and we can extend to medical diagnosis of any type of disease. 


\section{REFERENCES}

[1] Adlassnig K.P. Fuzzy set theory in medical diagnosis. IEEE Transactions on Systems, Man, and Cybernetics SMC 1986; vol.16: 260-265.

[2] Ahn J.Y., Kim Y.H., Mun K.S. , S.Y. Oh, B.S Han. A fuzzy method for diagnosis of headache. IEICE Trans. INF. \& SYST.; E.

[3] Ahn J.Y., Kim Y.H., Kim S.K.. A fuzzy differential diagnosis of headache applying linear regression method and fuzzy classification. IEICE Trans. INF. \& SYST. 2003; E86-D: 2790-2793.

[4] Atanassov K. Intuitionistic fuzzy sets. Fuzzy Sets and Systems; 20: 87-96.

[5] Atanassov K. Intuitionistic Fuzzy Sets: Theory and Applications. Physica -Verlag.; 63.
[6] Biswas R. Intuitionistic fuzzy relations. Bull. Sous. Ens. Flous. Appl. (BUSEFAL) 1986; 70: 22-29.

[7] Kumar S., Biswas R., Roy A.R.. An application of intuitionistic fuzzy sets in medical diagnosis. Fuzzy Sets and Systems 2001; 117: 209-213.

[8] Losch Breton. Appl. of Fuzzy Sets to the Diagnosis of Glaucoma. 18th Ann. Intel. Conf. of the IEEE Engg. in Medicine and Biology Society, Amsterdam 1997.

[9] Szmidt E., Kacprzyk J.. A measure for Intuitionistic Fuzzy Sets. Fuzzy sets and systems 2003; 121.

[10] Yao J.F, Yao J.S.. Fuzzy decision making for medical diagnosis based on fuzzy number and compositional rule of inference. Fuzzy Sets and Systems 2001; 120: 351366.

[11] Zadeh L A. Fuzzy Sets. Information and control 1965; 8: $338-353$ 